\title{
Energy Scavenging from Triaxial Tactile Sensing and Peltier Effect Sensing System
}

\author{
Muthuraj $\mathrm{B}^{\mathrm{a}, 1}$, Sundramoorthi $\mathrm{S}^{\mathrm{b}}$, Vasudevan $\mathrm{V}^{\mathrm{b}}$ \\ Jessica Angelyn $\mathrm{J}^{\mathrm{c}}$, Raveena $\mathrm{R}{ }^{\mathrm{c}}$ \\ ${ }^{a, b}$ Professor, Dept of E\&I, Panimalar Engineering College, Chennai \\ ${ }^{c} U G$ scholar,Dept of E\&I, Panimalar Engineering College, Chennai
}

\begin{abstract}
In the recent past there has been a significant increase in the research on vibration-based energy harvesting. Wherever mechanical movement exists, a lot of heat and vibration energy is wasted which could be used and converted as a supplement to the energy requirements. Towards this objective this project aims to provide a general theory that can be used for generating electricity from vibrating as well as heat body and store the acquired energy using advanced component called the super capacitor. A combination of Cantilever beam and MMA sensor is used for the sensing vibratory motion and the Peltier sensor is used for sensing the temperature of the source. The output obtained from the former source is converted into voltage using MMA technology and the latter is converted directly into the same. Boosted voltage is stored effectively with the help of super capacitor in primary storage device. The acquired voltage from the battery is $12 \mathrm{~V}$ with respect to this project. For the AC load, the current produced are $300 \mathrm{~mA}$. The output would change with respect to the vibrating and the temperature sources like generators or automotive engines
\end{abstract}

Keywords: Cantilever Beam, Peltier Sensor, MMA, Super Capacitor, DC-DC Boost converter

\section{Introduction}

Demands on heating, ventilating, and vibrating procedures in modern multistory buildings or in the industries are raising and there are various sensors, which can be used to gumption and govern the given procedure. Notwithstanding, in the event that we have insufficient cablegram framework, these sensors are not usable. The smart sensor should have the ability to force itself from the environment that is free of people. This technique is known as 'get-up-and-go' scavenging. Energy Department scavenging is by no means a new proposal. It is a process, by which free ambient vim is derived, captured, and Computer storage. Although non-traditional power source such as solar prison cell, photovoltaic cells, thermoelectric generators (Teg) and piezoelectric transducers are known sources of electrical force. Advancement in lowcontrol techniques is making it easier to create practical power energy administrative units, which have the capacity to gather and store them in high-limit capacitance.

\footnotetext{
${ }^{1}$ MuthurajB, Professor, Dept of E\&I, Panimalar Engineering College, Chennai;

E-mail: muthurajbose@gmail.com
} 
A Peltier impression sensing element senses thermal gradient formed between two dissimilar conductors and produces a voltage. Their capacity, size, equivalent series resistance and small leakage stream make them fit to be implemented into energy harvest power initiator. This capacitor is vital, because energy is stored after a small pulse and time between energy deliveries may vary from sec to minutes. The dynamical estimation method explains that a sensor component of vibratory power sensors has probability to distinguish multiple divisions of the power data through multiple vibration frequencies. The cantilever experiencing vibration power sensor is inserted in the elastic material for three-dimensional sensing by individual sensor component. The vibrating state changes by the outside material burden connected on the elastic surface via the elastic cantilever framework. The material burden is thus recognized as a resounding recurrence change While vibrating arms are defined by a dynamic compelled layer damping an ideal control of multi-arm mechanical framework was explored in a reenactment. The MMA7361L[6] is a micro machined accelerometer with low power, low profile capacitive emphasizing sign molding It is $0 \mathrm{~g}-\mathrm{d}$ which catches direct freefall, and g-Select which takes into consideration the determination between two sensitivities. Zero-g balance and affectability are industrial facility situated and require no outside gadgets. The MMA7361L incorporates a Sleep Mode that makes it perfect for handheld battery controlled gadgets. Surface micro machined, capacitive sensing cell (g-cell) and a sign molding is comprised in this gadget. It can be displayed as a set of pillars joined to a portable focal mass that move between altered shafts. The portable bars can be redirected from their stationary state by subjecting the framework to increasing speed. As the pillars append to the focal mass, the separation from them to the settled bars on one side will increment by the same sum as the separation to the altered shafts on the counter side declines. The variation in separation is a value of quickening. As the focal point shaft shifts with increasing speed, separation between the shafts change and each capacitor worth will change, $(C=A \varepsilon / D)$, where $A$ is the region of the bar, $\varepsilon$ is the dielectric consistent, and $\mathrm{D}$ is the separation between the bars. Warm sensors can likewise be utilized around the body to create power from a temperature distinction. The Peltier impact is regularly utilized for cooling electronic frameworks yet can likewise be utilized to create present from the temperature angle between the inner part and outer surface of any framework. This can be utilized to trickle encourage a battery or force a remote connection specifically.

\section{Proposed System}

Cantilever beam acts as device for enhancing the source of vibration. With the Micro machined accelerometer placed on the beam the conversion of mechanical energy generated from the movement of the beam to electrical energy is done. 


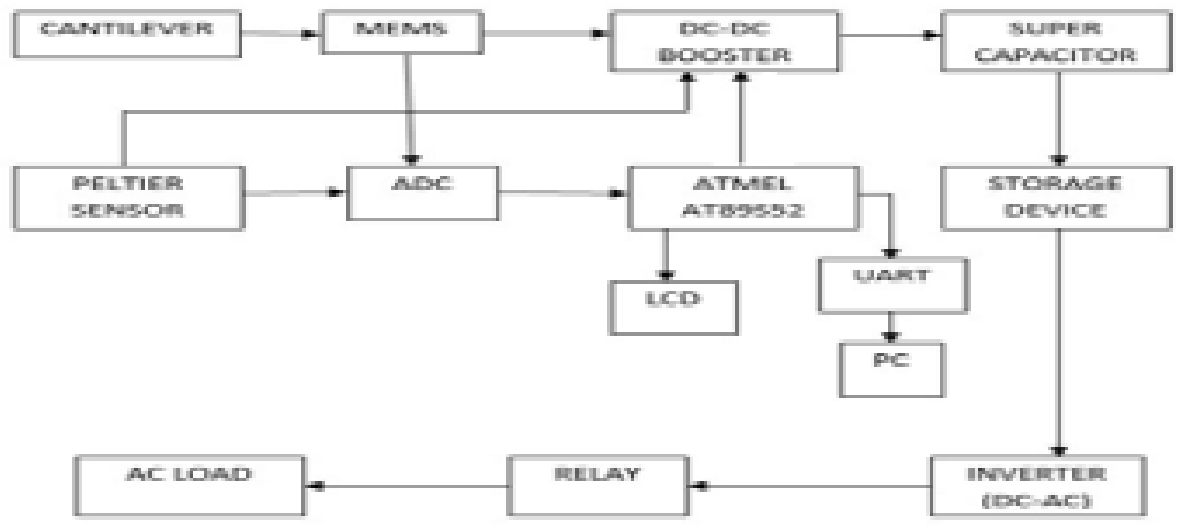

Figure 1. Proposed system

The output of Peltier sensor which is around (0-3.7) $\mathrm{V}$ and MMA which is around (2.8-3.3) V (adjusted by the Microcontroller and ADC's successive approximation technique to $3 \mathrm{~V}$ ) is given to the boost converter which gives a boosted output of $12 \mathrm{~V}$. The output of the DC to DC converter, which is used as an additional storage device and then to a battery. The stored energy is inverted from DC to AC using Micro LC Inverter and given to the relay, thus utilizing it for purposes like running $\mathrm{AC}$ loads and obtaining an output power of $30 \mathrm{~W}$. Similarly several KWs of power can be obtained by connecting the MMA in series. The above system can be fixed on motors, generators or any other vibratory and heat dissipating source thus scavenging energy from ambient waste energies.

\section{Converter Topology}

The basic boost converter is used to amplify the voltage. This operation also consists of using Q1 as a high speed device, with output voltage controlled by switching duty cycle. On turning Q1 ON, current travels from the input source through L and Q1. Current does not flow through D1 and the load. When GTO is switched off, L immediately reverses its EMF. It is added to the source voltage, and this 'current boosted voltage' now flows from the input source through L, diode and the load, recharging Capacitor as well. The received is therefore higher than the input voltage. The voltage step-up ratio is equal to

$$
\text { Vout } / \text { Vin }=1 /(1-\mathrm{D})
$$

Where the denominator is the proportion of the switching cycle when Q1 is turned off. So the step-up ratio is also equal to

$$
\text { Vout/Vin }=\text { T/Toff. }
$$




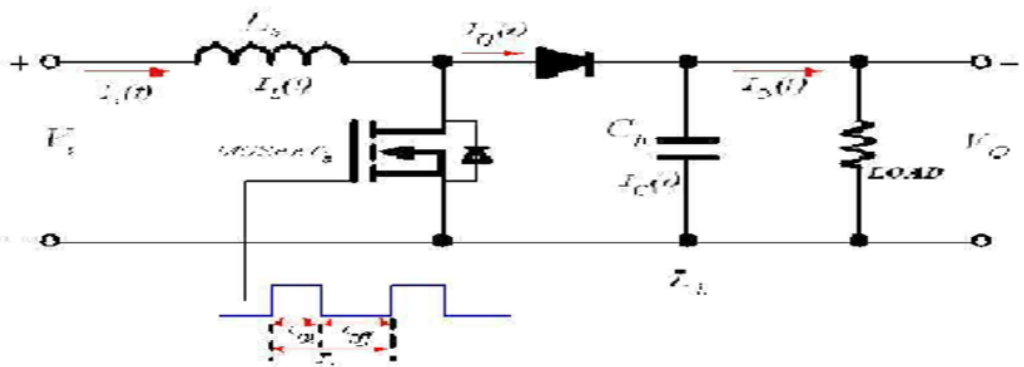

Figure 2. Boost Converter - General Circuit Diagram

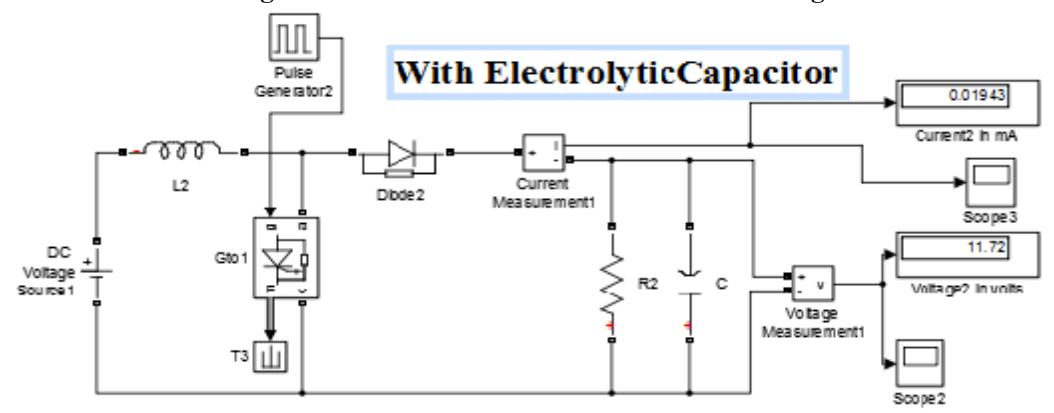

Figure 3. DC-DC boost converter with electrolytic capacitor

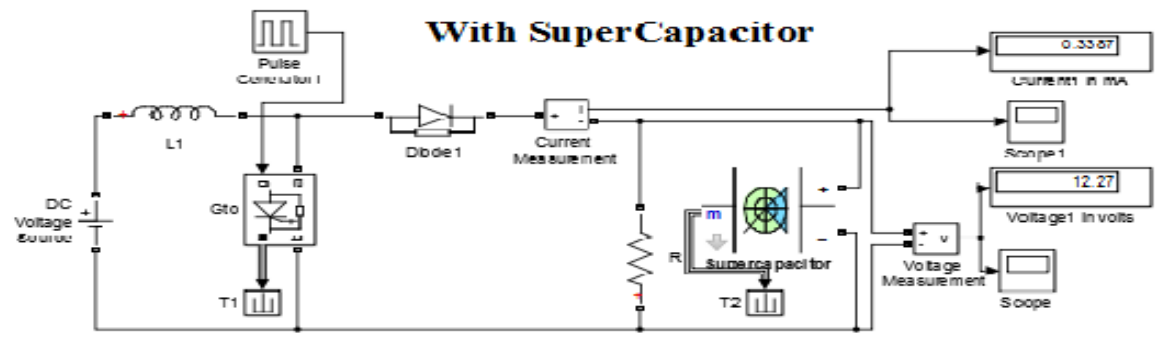

Figure 4. DC-DC boost converter with Super capacitor

Table 1. Design Parameters Of Capacitor

\begin{tabular}{|l|l|}
\hline Parameters & Values \\
\hline Input voltage & $4 \mathrm{v}$ \\
\hline Inductance & $5 \mathrm{mh}$ \\
\hline Capacitance & $495 \mathrm{mf}$ \\
\hline Load & $230 \mathrm{ohm}$ \\
\hline Output voltage & $12 \mathrm{v}$ \\
\hline Output current & $20 \mathrm{ma}$ \\
\hline Duty cycle & 0.75 \\
\hline
\end{tabular}




\section{Simulation Result and Discussion}

Simulation has been done by using MATLAB software and the results of output voltage, output current (load current) with electrolytic capacitor and super capacitor have been analyzed. Here the load current is enhanced from $20 \mathrm{~mA}$ to $300 \mathrm{~mA}$ by using super capacitor.

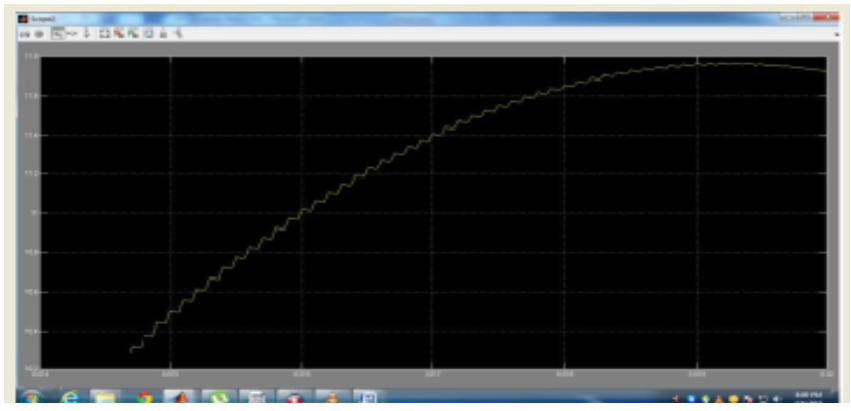

Figure 5. Output Voltage with Electrolytic Capacitor

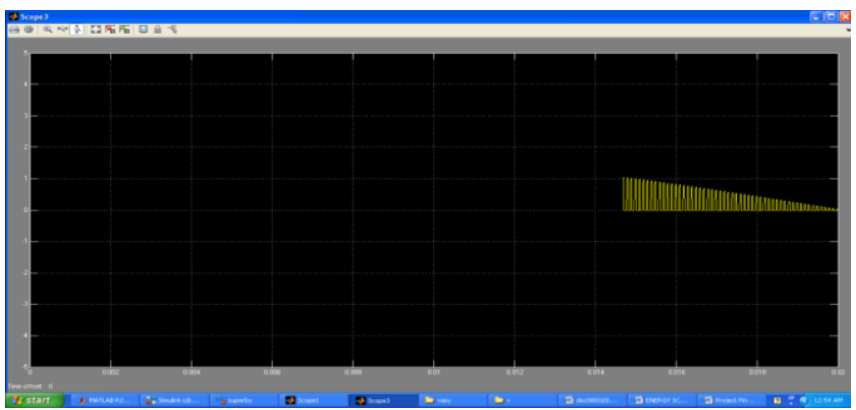

Figure 6. Output Current with Electrolytic Capacitor

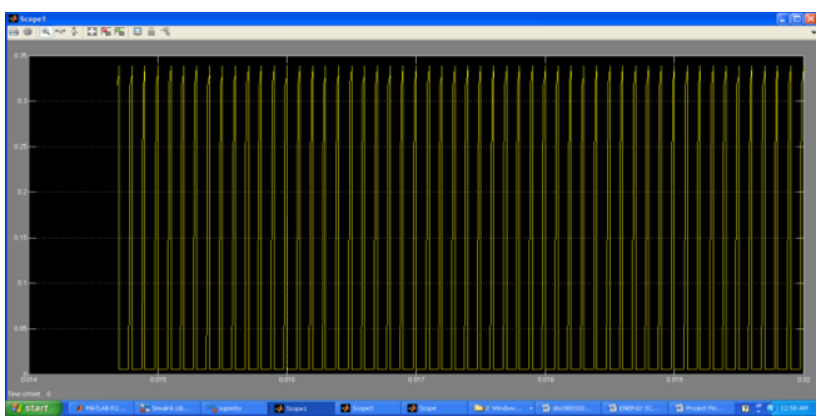

Figure 7. Output Current with Super Capacitor 
Table 2. Comparison of Output Voltage and Current

\begin{tabular}{|l|l|l|l|}
\hline NAME & $\begin{array}{l}\text { NORMAL } \\
\text { VALUE }\end{array}$ & $\begin{array}{l}\text { NORMAL } \\
\text { VALUE(EC) }\end{array}$ & $\begin{array}{l}\text { VALUEON } \\
\text { EXCITATION(SC) }\end{array}$ \\
\hline MEMS & $\begin{array}{l}0.3-0.6 \text { on } \\
\text { each channel }\end{array}$ & $\begin{array}{l}0.3-0.6 \text { on } \\
\text { each channel }\end{array}$ & $\begin{array}{l}1.3 \text { on each } \\
\text { channel }\end{array}$ \\
\hline DC-DC Booster & $2.8-3.3 \mathrm{~V}$ & $12 \mathrm{~V}$ & $12 \mathrm{~V}$ \\
\hline Output current & $15 \mathrm{~mA}$ & $20 \mathrm{~mA}$ & $300 \mathrm{~mA}$ \\
\hline Peltier Sensor & $0 \mathrm{~V}$ & $0 \mathrm{~V}$ & $12 \mathrm{~V}$ \\
\hline
\end{tabular}

\section{Conclusion}

The solution to the environmental and social problems is Green energy sources. Thus, a highly reliable and versatile system has been designed and developed to convert vibrations and temperature into electrical energy. This saves the cost spent for other renewable sources of energy. Ambient vibrations and degrees of temperatures are converted to electrical energy with the help of MEMS sensor. The sensor used is very sensitive and can sense the slightest of motion. The super capacitor used in this system helps to store the charges in the best way, as it has fast charging and discharging ability. So through this advancement the energy is obtained from the unused vibration and dissipating temperature which is an imitation of the green energy saving. Hence recycling of waste source of electrical form is done in a cyclic way, conserving energy effectively and efficiently.

\section{References:}

[1] Lee, S-K. And Yang, Y-S. .2011.Analysis of Vibration-energy-harvesting Devices based on a Piezoelectric Single Crystal Beam .Journal of the Korean Physical Society, Vol. 58, No. 3, p. 645-649.

[2] Yamashita,K.; YiYang;Nishimoto,T ; Furukawa,K. ; Noda,M. 2013 Piezoelectric VibratoryCantilever force Sensors and Axial Sensitivity for Individual Triaxial Tactile Sensing. Sensor journal, IEEE Vol. 13, No. 3 ;p: 1074 - 1080.

[3] Heung Soo Kim, Joo-Hyong Kim and Jaehwan Kim, 2011 ;A Review of Piezoelectric Energy Harvesting Based on Vibration . International Journal of Precision Engineering and Manufacturing vol. 12, no. 6, p. 1129-1141.

[4] Costa, F. and Ericka, M. 2005 .Energy Harvesting from Vibration using a Piezoelectric Membrane. Journal of physics. IV France 128 p. 187-193.

[5] Gurevich, Yu.G. and Logvinov, G.N. 2007 .Energy Harvesting for Industrial Networking.March 28, 2013 By European Editors, Contributed By Publitek Marketing Communications.Theory of thermoelectric cooling in semiconductor structures .Revista Mexicana De Fisica 53 (5) 337-349.

[6] Hua Yu, and Licheng Deng, 2014.A Vibration-Based MEMS Piezoelectric Energy Harvester and Power Conditioning Circuit. Sensors (14248220), Vol. 14 Issue 2, p3323.

[7] Jagannathan, S., Keith A. Corzine and Shahab Mehraeen .2010 .Energy Harvesting from Vibration with Alternate Scavenging Circuitry and Tapered Cantilever Beam',IEEE transactions on industrial electronics, Vol. 57, No. 3. p:820-830

[8] Atsuya Sato, Nov.3,201.New Polyacene Supercapacitors retain highest capacitance density and low ESR, while realizing a lower profile .Electronic Design Magazine . 